\title{
To Sow the Seeds of Innovation Consciousness in Junior Middle School Students Based on Material Engineering
}

\author{
Fang $\mathrm{Yao}^{1}$, Deng-Guang $\mathrm{Yu}^{2 *}$ \\ ${ }^{1}$ The Junior High School Affiliated to Shanghai Science and Technology University, No.50 Tu-Men Road, Yangpu District, \\ Shanghai 200093, P.R. China \\ ${ }^{2}$ School of Materials Science \& Engineering, University of Shanghai for Science \& Technology, Shanghai 200093, China. \\ Corresponding authors E-mail: ydg017@usst.edu.cn
}

\begin{abstract}
Nowadays, innovation education is very important for fostering advanced social labors. This requires that the teenage students should be cultivated the innovation consciousness as early as possible. In this paper, some new methods are disclosed for sowing the innovation consciousness seed to the students in the junior middle school. With a series of elements in the process of material engineering, teaching materials for carrying out innovation consciousness teaching on students are showed. These contents include: 1 ) the exhibitions of material innovations from corncobs to zein powders, and to zein electrospun nanoribbons; 2) the comparison between the traditional weaving and spinning techniques with the advanced electrospinning for making the students have more awareness on technological innovations; 3) the expanding applications of zein from noodles to packing bags, and to absorbents of polluted dyes for material application innovations. This paper paves a new way for implementing innovation education on middle school with materials refined from the advanced nanotechnology and nanomaterials.
\end{abstract}

Keywords-Innovation consciousness; Junior middle school; Scientific phenomena; Electrospinning; Nanomaterials

\section{INTRODUCTION}

The 33rd China Adolescents Science \& Technology Innovation Contest, held in Chongqing from 14 to 20 August 2018, has achieved fruitful results. The levels of innovation by the adolescents are always rising during the past several decades [1]. The experiences from the attended groups are that innovation consciousnesses should be poured into the students' brains as early as possible.

Naturally, the human brain is not fully developed by the time a person reaches puberty. Between the ages of 10 and 25, the brain undergoes changes that have important implications for behavior. The brain reaches $90 \%$ of its adult size by the time a person is six years of age. Thus, the brain does not grow in size much during adolescence. However, the creases in the brain continue to become more complex until the late teens. The biggest changes in the folds of the brain during this time occur in the parts of the cortex that process cognitive and emotional information. Correspondingly, adolescence is a time for rapid cognitive development. Piaget describes adolescence as the stage of life in which the individual's thoughts start taking more of an abstract form and the egocentric thoughts decrease. This allows the individual to think and reason in a wider perspective. The thoughts, ideas and concepts developed at this period of life greatly influence one's future life, playing a major role in character and personality formation [2].

During the growth of a person, the innovation education should be conducted in a continuous manner, from the primary school to the secondary middle school, to the high school, university and even to the professional institutions (Figure 1). Certainly, at different time period, the requests should be different. For example, the adults and the professional persons need to exhibit their innovation results to demonstrate their qualifications. But as fast as the students concerned, it should be all right that they have clear awareness about their innovative behaviors and activities, innovation results are relatively less important then.

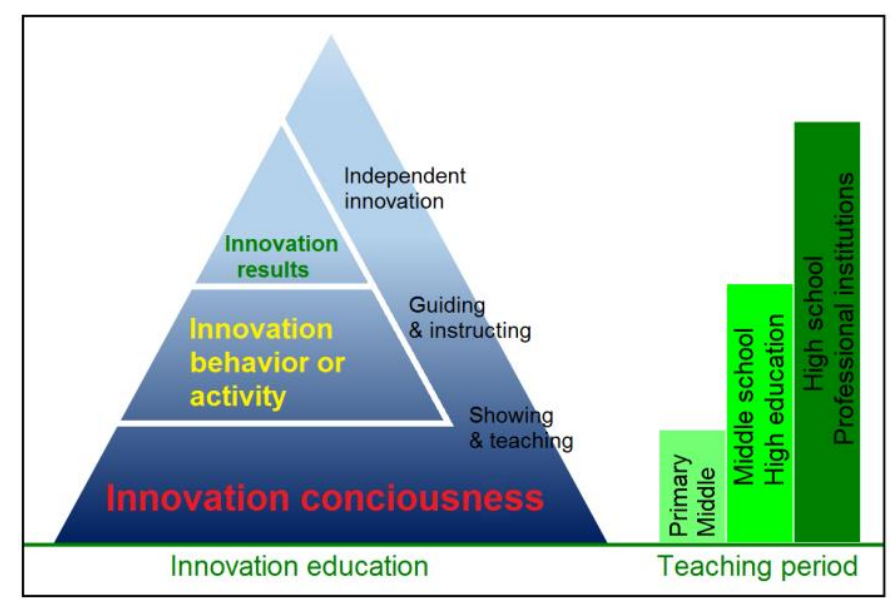

Fig. 1 The progresses from innovation consciousness to innovation activity and to innovation results should be all at the innovation education range.

As for the primary and middle school students, the most important thing should be that their innovation consciousnesses are cultivated and strengthened in a continuous manner. For easy beginning, the teenage students can be imparted about innovations through some scientific experiments. After the showing and teaching stage, they can be guided and instructed to carry out some new experiments, leading them to "do" innovations themselves. Certainly, they can implement innovations finally when they become a useful labor to our modern society. 


\section{ADVANCED NANOTECHNOLOGY AND NANOMATERIALS CAN PROVIDE ABUNDANT TEACHING MATERIALS FOR INNOVATION CONSCIOUSNESS CULTIVATION}

During the development of our human history, innovation always has a close relationship with the knowledge. Just as "chance favors the one with a prepared mind", innovation favors the one with enough knowledge reserve ! Knowledge acquisition involves complex cognitive processes processes: perception, communication, and reasoning.

Innovation is about a "new idea, device or method". It can be defined as something original and more effective and, as a consequence, new, that "breaks into" the market or society. Innovation often manifests itself via the engineering process, when the problem being solved is of a technical or scientific nature. Consciousness is the state or quality of awareness, or, of being aware of an external object or something within oneself. It has been defined variously in terms of sentience, awareness, quality, subjectivity, the ability to experience or to feel,wakefulness, having a sense of self-hood or soul, the fact that there is something "that it is like" to "have" or "be" it, and the executive control system of the mind. Thus, innovation consciousness can be viewed as a quality of being aware of an external innovations within oneself's knowledge system.

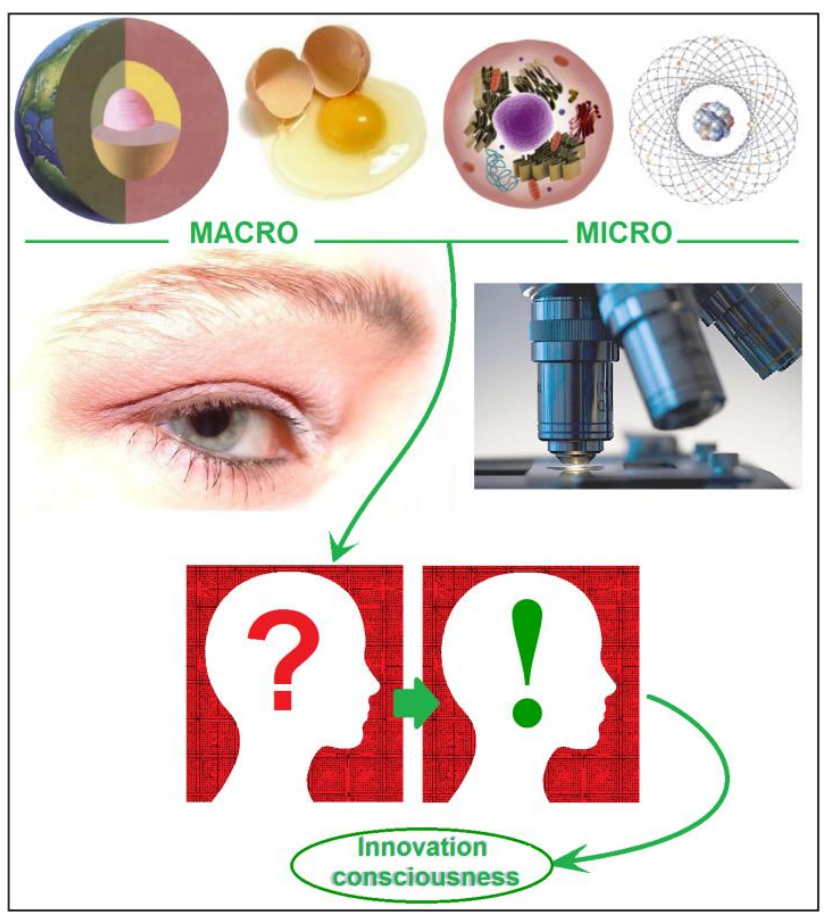

Fig. 2 Just as our knowledge achieved from the phenomena at macro scale, advanced nanotechnology and nanomaterials can provide abundant teaching materials for innovation consciousness cultivation.

In ancient time, the natural phenomena such as "wind, rain, thunder and electricity" have comprised the materials for many mythologies. The reasonable explanations about these phenomena are the well-known knowledge today, which are also teaching materials in the text books in the primary and also secondary schools. The recognization and confirmation processes of these knowledge are accompanied with numerous innovations. Similarly in today' $\mathrm{s}$ nano era, the advanced nanotechnology and nanomaterials should bring out many knowledges about the micro world, and meanwhile provide abundant teaching materials for innovation consciousness cultivation (Figure 2).

\section{INNOVATION CONSCIOUSNESS ABOUT MATERIALS}

For the Junior high school students, a systematic process about the preparation, observation, and applications of an advanced functional nanomaterials (nanoribbons of zein) can be made full of usage to show them innovations, and correspondingly to foster their innovation consciousnesses.

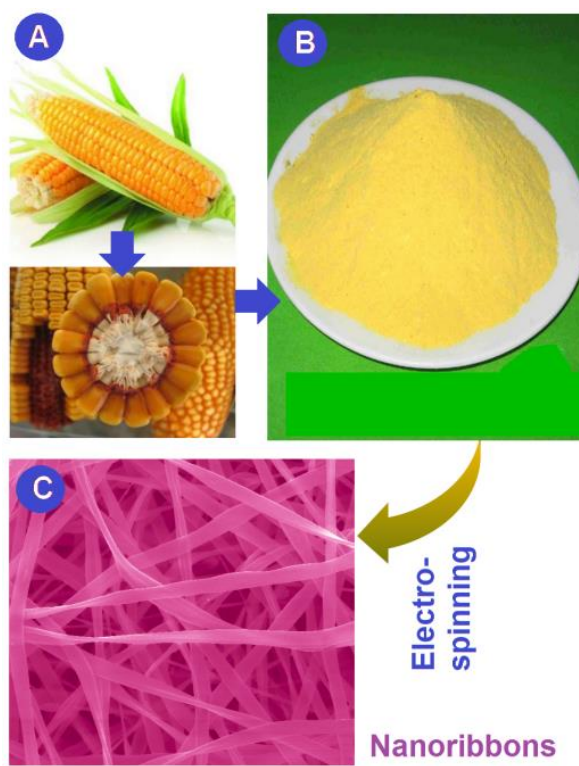

Fig. 3 Innovation consciousness teaching material about material transitions: A-corncob; B-zein; C-nanoribbons.

Shown in Figure 3 is an innovation consciousness teaching material about material transitions. The corncobs and their cross-sections in Figure 3A is familiar to everyone, including all the students in junior high school. Zein powders (Figure 3B) are an extracted product from the corns, which are a plant protein. It has a very strange solubility, insoluble in both water and also ethanol, but soluble in an aqueous solution (w/w) consisting of $60 \%$ to $90 \%$ ethanol. These contents should be unfamiliar to the students [3-4]. Through electrospinning, zein powders can be converted into nanoribbons, which are exhibited in Figure 3C. These zein nanoribbons should be a totally new concept to the students.

The exhibitions from corncobs to zein powders, and to zein electrospun nanoribbons should be excellent teaching materials about material engineering, materials formation and processing, but the most important aspect is about the creation of new material, i.e. material innovation. Thus, these materials' conversion should be an example for fostering the students' innovation consciousnesses about materials. 


\section{INNOVATION CONSCIOUSNESS ABOUT MODERN TECHNOLOGIES}

Electrospinning, the process that is applied for converting zein powders to zein nanoribbons, is presently one of the hottest nano techniques. It has been exploited to create nanofibers from a wide variety of macromolecules (such as polymers and proteins) [5-13]. These nanofibers have found potential applications in almost all the applied scientific fields [14-19]. Figure 4A is a diagram about a modified coaxial electrospinning process. Figure $4 \mathrm{~B}$ is a digital picture captured during the preparation process for producing zein nanoribbons from zein ethanol aqueous ( $75 \%$ in weight) solution. The inset is a typical Taylor cone, showing the robust and stable preparation processes [17].

In ancient China, Huang Daoba is famous because she made important contributions to the reform of cotton spinning tools (Figure 4C). She had also summed up the weaving techniques learned from the $\mathrm{Li}$ people and her own practical experience into a set of relatively advanced weaving techniques, such as staggered yarns, color matching, heddles and yarns. The comparison between the traditional weaving and spinning techniques with the advanced electrospinning can make the students have more awareness about technological innovations. Here, the key element in the electrospinning process is the application of electrostatic forces in producing nanofibers. In contrast, the traditional spinning utilizes the mechanical forces to weave. Based on the increase of innovation consciousnesses on modern technologies, it should be easier to tell students about electrospraying, coaxial electrohydrodynamic atomization, and other related modern techniques [20-29].

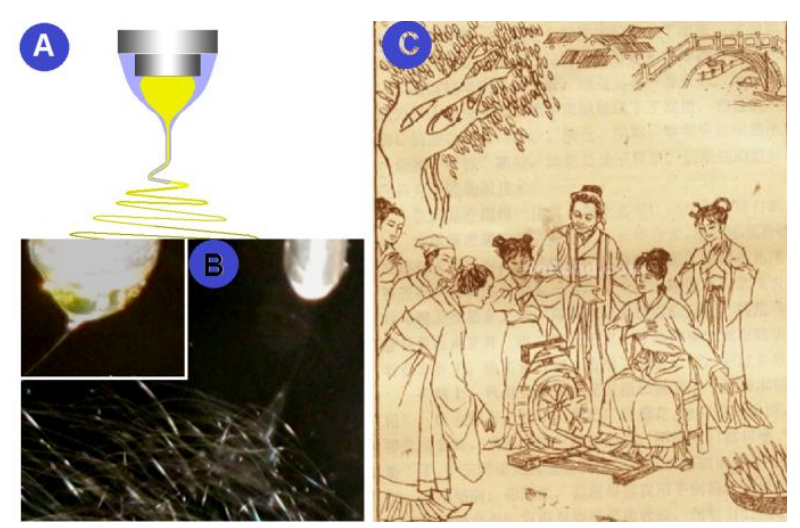

Fig. 4 Innovation consciousness about modern techniques.

\section{INNOVATION CONSCIOUSNESS ABOUT NEW APPLICATIONS OF MATERIALS}

As a plant protein, zein is frequently exploited in the food industry. For example, zein can be added into the flour to make the noodles more elastic (Figure 5A). About one decade before, zein was exploited as packing bags due to its good biocompability and biodegradability (Figure 5A). The progresses happened previously about the application of zein can be innovation teaching materials to the students for cultivating their awareness in this aspect. The further progresses occurred today should provide stronger impact on the students about application innovation, increasing their innovation consciousnesses. Shown in Figure 5C, a contrast of the color in two bottles tells the story that the zein nanoribbons can be exploited to absorb blue dye from the polluted water. When the students have enough innovation consciousnesses about material applications, they can try to conduct similar innovations all by themselves.

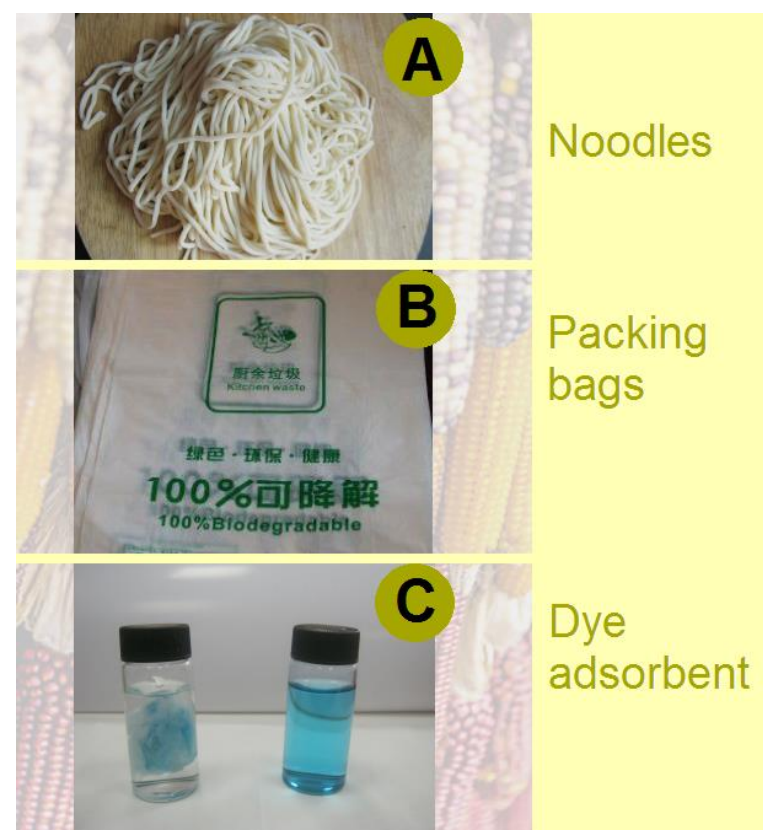

Fig. 5 Innovation consciousness about new applications of zein.

\section{SUMMARY}

An engineering process about material treatment, i.e. from zein powder to zein nanoribbons using electrospinning and their applications in dye absorbing, is shown in this paper. Three elements are exploited as teaching materials for fostering the innovation consciousnesses of student in junior high school. First, the exhibitions from corncobs to zein powders, and to zein electrospun nanoribbons are shown for explaining material innovations. Later, the comparison between the traditional weaving and spinning techniques with the advanced electrospinning is carried out for making the students have more awareness about technological innovations. Finally, the applications of zein from addition in noodles to degradable packing bags, and to absorbents of polluted dyes are concluded for material application innovation teaching. These contents extracted from the electrospinning and its product nanofibers and nanoribbons should be also fine materials for the school-based training in the classroom for teachers in junior high school.

\section{ACKNOWLEDGMENT}

The financial supports are from the Shanghai Education Science Research Project (C17058) and the National Nature Science Foundation of China (51373101). 


\section{REFERENCES}

[1] Anonymity. http://castic.xiaoxiaotong.org/, 21-Aug-2018.

[2] Choudhury, S.; Blakemore, S.-J.; Charman, T. (2006). "Social cognitive development during adolescence". Social Cognitive and Affective Neuroscience. 1 (3): 165-174.

[3] Z.P. Liu, Y.Y. Zhang, D.G. Yu, D. Wu, and H.L. Li, "Fabrication of sustained-release zein nanoparticles via modified coaxial electrospraying,” Chem. Eng. J., vol.334, pp.807-816, 2018.

[4] D.G. Yu, J.J. Li, G.R. Williams, and M. Zhao, "Electrospun amorphous solid dispersions of poorly water-soluble drugs: A review," J. Control. Release, Doi:10.1016/j.jconrel.2018.08.016.

[5] D.G. Yu, C. Yang, M. Jin, G.R. Williams, H. Zou, X. Wang, et al, "Medicated Janus fibers fabricated using a Teflon-coated side-by-side spinneret," Colloid. Surface B, vol.138, pp.110-116, Feburary 2016.

[6] Y.H. Wu, D.G. Yu, H.P. Li, X.Y. Wu, and X.Y. Li, "Medicated structural PVP/PEG composites fabricated using coaxial electrospinning," e-Polymers, vol.17, pp.39-44, January 2017.

[7] C. Yang, D.G. Yu, D. Pan, X.K. Liu, X. Wang, S.W.A. Bligh, et al, "Electrospun pH-sensitive core-shell polymer nanocomposites fabricated using a tri-axial processes," Acta Biomater., vol.35, pp.77-86, April 2016.

[8] G.Z. Yang, H.P. Li, J.H. Yang, J. Wan, and D.G. Yu, "Influence of working temperature on the formation of electrospun polymer nanofibers," Nanoscale Res. Lett., vol.12, Article 15, January 2017.

[9] Y.Y. Yang, Z.P. Liu, D.G. Yu, K. Wang, P. Liu, X. Chen, "Colon-specific pulsatile drug release provided by electrospun shellac nanocoating on hydrophilic amorphous composites," Int. J. Nanomed., vol.2018, pp. 2395-2404, 2018.

[10] Q. Wang, D.G. Yu, L.L. Zhang, X.K. Liu, Y.C. Deng, and M. Zhao, "Electrospun hypromellose-based hydrophilic composites for rapid dissolution of poorly water-soluble drug," Carbohydr. Polym., vol.174, pp.617-625, Oct, 2017.

[11] Y. Yang, W. Li, D.G. Yu, G. Wang, G.R. Williams, Z. Zhang, "Tunable drug release from nanofibers coated with blank cellulose acetate layers fabricated using tri-axial electrospinning," Carbohydr. Polym., vol.203, pp.228-237, 2019

[12] K. Wang, X.K. Liu, X.H. Chen, D.G. Yu, Y.Y. Yang, and P. Liu, "Electrospun hydrophilic Janus nanocomposites for the rapid onset of therapeutic action of helicid," ACS Appl. Mater. Interfaces, vol.10, pp.2859-2867, 2018.

[13] G.Z. Yang, J.J. Li, D.G. Yu, M.F. He, J.H. Yang, and G.R. Williams, "Nanosized sustained-release drug depots fabricated using modified tri-axial electrospinning," Acta Biomater., vol.53, pp.233-241, April 2017.

[14] Y. Xu, J.J. Li, D.G. Yu, G.R. Williams, J.H. Yang, and X. Wang, "Influence of the drug distribution in electrospun gliadin fibers on drug-release behavior,” Eur. J. Pharm. Sci., vol.106, pp.422-430, August 2017.

[15] Z. Zhang, W. Li, G. Wang, Y.L. Qu, and D.G. Yu, "Electrospun 4th generation solid dispersions of poorly water-soluble drug utilizing two different processes,” J. Nanomater. Vol.2018, Article ID 2012140, 2018.
[16] Q. Wang, D.G. Yu, S.Y. Zhou, C. Li, and M. Zhao, "Fabrication of amorphous electrospun medicated-nanocomposites using a Teflon-based concentric spinneret," e-Polymer, vol.18, pp.3-11, 2018.

[17] H.F. Wen, C. Yang, D.G. Yu, X.Y. Li, D.F. Zhang, "Electrospun zein nanoribbons for treatment of lead-contained wastewater," Chem. Eng. J., vol.290, pp.263-272, 2016.

[18] D.G. Yu, J.J. Li, M. Zhang, and G.R. Williams, "High-quality Janus nanofibers prepared using three-fluid electrospinning," Chem. Commun., vol.53, pp.4542-4545, April 2017.

[19] J.J. Li, Y.Y. Yang, D.G. Yu, Q. Du, X.L. Yang, "Fast dissolving drug delivery membrane based on the ultra-thin shell of electrospun core-shell nanofibers,” Eur. J. Pharm. Sci., vol.107, pp. 195-204, 2018.

[20] Y.Y. Yang, M. Zhang, K. Wang, and D.G. Yu, "pH-sensitive polymer nanocoating on hydrophilic composites fabricated using modified coaxial electrospraying," Mater. Lett., vol.227, pp. 93-96, 2018.

[21] M. Jin, D.G. Yu, X. Wang, C.F.G.C. Geraldes, G.R. Williams, and S.W.A. Bligh, "Electrospun contrast agent-loaded fibers for colon-targeted MRI," Adv. Healthcare Mater., vol.5, pp.977-985, April 2016.

[22] Y.H. WU, H.P. Li, X.X. Shi, J. Wan, Y.F. Liu, and D.G. Yu, "Effective utilization of the electrostatic repulsion for improved alignment of electrospun nanofibers," J. Nanomater., vol.2016, Article ID2067383, 2016.

[23] X.Y. Li, Z.B. Zheng, D.G. Yu, X.K. Liu, Y.L. Qu, and H.L. Li, "Electrosprayed sperical ethylcellulose nanoparticles for an improved sustained-release profile of anticancer drug," Cellulose, vol.24, pp.5551-5564, 2017.

[24] Y.Y. Yang, M. Zhang, Z.P. Liu, K. Wang, and D.G. Yu, "Meletin sustained-release gliadin nanoparticles prepared via solvent surface modification on blending electrospraying," App. Surf. Sci., vol.434, pp.1040-1047, 2018.

[25] X. Liu, W. Shao, M. Luo, J. Bian, D.G. Yu, "Electrospun blank nanocoating for improved sustained release profiles from medicated gliadin nanofibers," Nanomaterials, vol.8, Article ID 184 (11 pages), 2018.

[26] W. Huang, Y. Yang, B. Zhao, G. Liang, S. Liu, X.-L. Liu, and D.G. Yu, "Fast dissolving of ferulic acid via electrospun ternary amorphous composites produced by a coaxial process," Pharmaceutics, vol.10, Article ID115 (12 pages), 2018

[27] K. Wang, H.F. Wen, D.G. Yu, Y. Yang, and D.F. Zhang, "Electrosprayed hydrophilic nanocomposites coated with shellac for colon-specific delayed drug delivery," Mater. Design, vol.143, pp.248-255, 2018.

[28] Z.P. Liu, L.L. Zhang, Y.Y. Yang, D. Wu,G. Jiang, and D.G. Yu, "Preparing composite nanoparticles for immediate drug release by modifying electrohydrodynamic interfaces during electrospraying," Powder Technol., vol.327, pp.179-187, 2018.

[29] X. Liu, Y. Yang, D.G. Yu, M.J. Zhu, M. Zhao, G.R. Williams, "Tunable zero-order drug delivery systems created by modified triaxial electrospinning," Chem. Eng. J., vol. 356, pp.886-694, 2019. 